\title{
The dysregulated Pink1- drosophila mitochondrial proteome is partially corrected with exercise
}

\author{
Brad Ebanks ${ }^{1,}{ }^{*}$, Thomas L Ingram ${ }^{1,}{ }^{*}$, Gunjan Katyal ${ }^{1}$, John R Ingram ${ }^{2}$, Nicoleta Moisoi ${ }^{3}$, Lisa \\ Chakrabarti $^{1,4}$
}

${ }^{1}$ School of Veterinary Medicine and Science, University of Nottingham, Sutton Bonington, LE12 5RD, UK

${ }^{2}$ Ullswater Avenue, West End, Southampton, UK

${ }^{3}$ Leicester School of Pharmacy, Leicester Institute for Pharmaceutical Innovation, De Montfort University, The Gateway, Leicester LE1 9BH, UK

${ }^{4} \mathrm{MRC}$ Versus Arthritis Centre for Musculoskeletal Ageing Research, UK

*Equal contribution

Correspondence to: Lisa Chakrabarti; email: lisa.chakrabarti@nottingham.ac.uk Keywords: PINK1, drosophila, mitochondria, exercise, proteomics

Received: February 11, $2021 \quad$ Accepted: May 20, $2021 \quad$ Published: June 1, 2021

Copyright: (C) 2021 Ebanks et al. This is an open access article distributed under the terms of the Creative Commons Attribution License (CC BY 3.0), which permits unrestricted use, distribution, and reproduction in any medium, provided the original author and source are credited.

\section{ABSTRACT}

One of the genes which has been linked to the onset of juvenile/early onset Parkinson's disease (PD) is PINK1. There is evidence that supports the therapeutic potential of exercise in the alleviation of PD symptoms. It is possible that exercise may enhance synaptic plasticity, protect against neuro-inflammation and modulate LDopa regulated signalling pathways. We explored the effects of exercise on Pink1 deficient Drosophila melanogaster which undergo neurodegeneration and muscle degeneration. We used a 'power-tower' type exercise platform to deliver exercise activity to Pink1 ${ }^{-}$and age matched wild-type Drosophila. Mitochondrial proteomic profiles responding to exercise were obtained. Of the 516 proteins identified, 105 proteins had different levels between Pink1- and wild-type non-exercised Drosophila. Gene ontology enrichment analysis and STRING network analysis highlighted proteins and pathways with altered expression within the mitochondrial proteome. Comparison of the Pink1- exercised proteome to wild-type proteomes showed that exercising the Pink1-Drosophila caused their proteomic profile to return towards wild-type levels.

\section{INTRODUCTION}

Parkinson's disease (PD) is a progressive, irreversible neurodegenerative condition which affects over 6 million people across the globe [1]. The greatest risk factor for PD is advancing age, and with the number of people over the age of 60 expected to exceed 2 billion by the year 2050 (currently estimated to be over 900 million) there will soon be significantly higher numbers of people living with PD [2]. The classical physical symptoms are known to be resting tremor, rigidity and bradykinesia. It is now also known that symptoms of PD include reduced quality of sleep as well as both cognitive impairments and poor mental health. In terms of the pathophysiology of the disease, the death of pigmented dopaminergic neurons in the substantia nigra pars compacta in PD patients is critical [3]. Molecular characteristics of PD include the aggregation of $\alpha$ synuclein leading to Lewy body formation, alongside mitochondrial dysfunction $[4,5]$.

Hereditary forms of PD can be either autosomal dominant or autosomal recessive, dependent upon the mutant gene involved. In both dominant and recessive forms of hereditary PD, autophagic and lysosomal pathways are both mechanistically implicated [6-8]. One of the critical pathways which has been linked to the onset of juvenile/early onset PD is the PINK1/ 
Parkin mitophagy pathway, a form of autophagy for the degradation of dysfunctional mitochondria. The role of mitophagy is to provide a quality control mechanism for the mitochondrial population within a cell, and this is a particularly crucial function in energetically demanding neuronal cells [9].

Mechanistically, PINK1 localizes with outer mitochondrial membrane (OMM) of depolarized mitochondria and then recruits and activates the E3 ubiquitin-ligase activity of Parkin via phosphorylation of its Ser65 residue [10, 11]. PINK1 has also been shown to phosphorylate the Ser65 residue of Ubiquitin, which aids in the activation of Parkin's E3 ligase activity $[12,13]$. Ultimately these events lead to the ubiquitination of OMM proteins by Parkin, the autophagic machinery then degrades the ubiquitinated mitochondria [14]. Mutations in PINK1 (and Parkin) can result in autosomal recessive juvenile onset PD, with onset before the age of 40 years old [15]. While this form of $\mathrm{PD}$ is rare, a comprehensive understanding of it can improve the outcomes of patients with PINK1 mutations and also those with idiopathic PD due to their shared pathophysiology [16]. A recent publication by Sliter et al. reported that Pinkl and Parkin mitigate STING induced inflammation, where both Pinkl ${ }^{-/}$and $\mathrm{Prkn}^{-/}$mice under exhaustive exercise have a strong inflammatory phenotype that is rescued by the concurrent loss of the STING pathway [17]. In the same year, Zhong et al. reported that newly synthesised oxidised mitochondrial DNA is exported to the cytosol and stimulates another of the innate immune responses, the NLRP3 inflammasome [18].

Given the overlapping biology between PINK1 loss of function in PD and other forms of genetic and sporadic PD, PINK1 null mutants of animal models are hugely useful in studies of PD. Pinkl loss of function Drosophila models were first developed in 2006, shortly after the first parkin loss of function mutant Drosophila models were being utilised in research [19-21]. These first studies found that Pinkl loss of function resulted in mitochondrial dysfunction, compromised fertility in males, indirect flight muscle degeneration and associated locomotor defects, increased sensitivity to oxidative stress, and dopaminergic degeneration (Park et al., 2006) [19]. Parkin overexpression rescued many of the defects observed in the Pinkl mutants, indicating the downstream function of Parkin in the now established PINK1/Parkin mitophagy pathway, reviewed here [22]. More recent studies using Pink1 mutant Drosophila have found that their neurons exhibit decreased levels of synaptic transmission, defective fission and reduced ATP levels due to decreased COXI and COXIV activity as well as non-motor symptoms such as learning and memory deficits, weakened circadian rhythms and electrophysiological changes in clock-neurons [23-25].

It was first observed in 1992 that participation in exercise reduced the risk of the onset of PD in later years, while later data showed that this protection against PD risk is more obvious in males [26, 27]. Many groups have presented data that show the therapeutic potential of exercise in the alleviation of patient symptoms [28-30]. The biochemical mechanisms that would explain these observations are still unclear, but current evidence suggests that exercise may enhance synaptic plasticity, protect against neuroinflammation and modulate L-Dopa regulated signalling pathways [31-33].

In this study we aimed to analyse the biochemical changes induced by exercise in the mitochondrial proteome of the Pinkl loss of function mutant (Pink1 $1^{-}$) Drosophila. As exercise is reported to both reduce the risk of onset and improve outcomes for Parkinson's disease patients, we sought to characterise the biochemical changes that could underpin this improvement in our model of Parkinson's disease. We focused on the mitochondria as their dysfunction is widely associated with Parkinson's disease, and the Pink $1^{-}$genetic model has a disrupted mitophagy pathway due to the absence of a functional PINK1 protein.

\section{MATERIALS AND METHODS}

\section{Drosophila stocks}

Fly stocks were kindly provided to NM by Miguel Martins (MRC Toxicology Unit) and Alex Whitworth (MRC Mitochondrial Biology Unit). Fly stocks and crosses were maintained on standard cornmeal agar media at $25^{\circ} \mathrm{C}$ in a 12:12 light-dark cycle. The experiments were performed on males: wild type (genotype w1118) and Pinkl' (genotype Pink1B9/Y).

\section{Drosophila exercise}

Approximately twenty wild-type control or Pink1 Drosophila, 1-4 days post-eclosion, were separated into glass vials filled with $5 \mathrm{ml}$ food. Exercised group vials were stoppered with cotton wool $6 \mathrm{~cm}$ from the food; non-exercised group vials were stopped with cotton wool $1 \mathrm{~cm}$ from the food, creating a physical barrier to activity. Both exercised and non-exercised groups were placed in racks on the ICE machine (Supplementary Material) for 30 minutes per day for 7 days. The Drosophila were exercised in the morning each day and were sacrificed by freezing at $-80^{\circ} \mathrm{C}$ one hour after the final exercise bout. Comparison groups were exercised and non-exercised wild-type and Pink1 ${ }^{-}$Drosophila. 


\section{Mitochondrial isolation}

Groups of twenty wild-type or Pink1-Drosophila were homogenised in 100-200 $\mu$ mitochondrial extraction buffer $(50 \mathrm{mM}$ Tris-Cl pH 7.4, 100mM KCL, $1.5 \mathrm{mM}$ $\mathrm{MgCl} 2,1 \mathrm{mM}$ EGTA, $50 \mathrm{mM}$ HEPES and $100 \mathrm{mM}$ sucrose) by 5 minutes of manual homogenisation using a 1.2-2ml Eppendorf micro-pestle (Sigma-Aldrich). The homogenate was centrifuged at $800 \mathrm{~g}$ for 10 minutes, at $4^{\circ} \mathrm{C}$, to remove the insoluble fraction. Supernatants from the first centrifugation were centrifuged at $1,000 \mathrm{~g}$ for 10 minutes at $4^{\circ} \mathrm{C}$ to pellet the nuclear fraction. Supernatants from the second centrifugation were centrifuged at $13,200 \mathrm{~g}$ for 30 minutes at $4^{\circ} \mathrm{C}$ to pellet the mitochondrial fraction. The protein content was determined by Bradford assay $(\mu \mathrm{g} / \mu \mathrm{l})$ and mitochondrial fractions were stored at $-80^{\circ} \mathrm{C}$.

\section{D-gel electrophoresis}

$50 \mu \mathrm{g}$ of the mitochondrial fraction were added to rehydration solution (8M urea, 2\% CHAPS, 2\% IPG Buffer, 0.1\% bromophenol blue). 20mM DTT was added to an aliquot of rehydration solution directly before use. The standard protocol according to manufacturer instructions was followed [34]. Briefly, sample was applied to rehydrate ZOOM IPG strips for an hour at room temperature followed by iso-electric focusing using the ZOOM IPG (Life Technologies) system and $\mathrm{pH}$ 3-10 (non-linear) ZOOM IPG strips. Gels were stained (SimplyBlue ${ }^{\mathrm{TM}}$ SafeStain, Life Technologies) and imaged (ImageQuant 300, GE Healthcare Life Sciences). Analyses were performed using SameSpots software (Totallab) (one-way ANOVA). Three pooled biological replicates were included for each of the four groups.

Samples were analysed by the Centre of Excellence in Mass Spectrometry at University of York [35]. Briefly, proteins were reduced and alkylated, followed by digestion in-gel with trypsin. Matrix Assisted Laser Desorption Ionization Tandem Time-of-Flight mass spectrometry (MALDI-TOF/MS) was used to analyse the samples. The generated tandem MS data was compared against the NCBI database using the MASCOT search programme to identify the proteins. De novo sequence interpretation for individual peptides were inferred from peptide matches.

\section{Label-free proteomics}

$30 \mu \mathrm{g} / \mu \mathrm{l}$ of each mitochondrial fraction was prepared with 4X LDS sample buffer and 4mM DTT. Samples were run in triplicate on a $4-12 \%$ Bis-Tris gel in $1 \mathrm{X}$ MES SDS running buffer for 40 minutes at 200V (all Invitrogen). Three biological replicates were run for each of the four groups. The whole, individual gel lanes were excised and placed into separate Eppendorf tubes.

Samples were analysed by the Centre of Excellence in Mass Spectrometry at University of York [35]. Briefly, protein was in-gel digested post-reduction and alkylation. The resulting extracted peptides were analysed over 1-hour LC-MS acquisitions with elution from a 50cm, C18 PepMap column onto a Thermo Orbitrap Fusion Tribrid mass spectrometer using a Waters mClass UPLC. Extracted tandem mass spectra were searched against the combined Drosophila melanogaster and Saccharomyces cerevisiae subsets of the UniProt database. Protein identifications were filtered to achieve $<1 \%$ false discovery rate as assessed against a reverse database. Identifications were further filtered to require a minimum of two unique peptides per protein group.

For relative label-free quantification, extracted ion chromatograms for identified peptides were extracted and integrated for all samples. A maximum mass deviation of $3 \mathrm{ppm}$ and retention time drift of 3 mins were set. Resulting quantifications were further filtered to an arbitrary PEAKS quality factor of 5 for feature mapping and required a minimum of two aligned features from a minimum of two unique peptides per protein quantification. Protein abundances were normalised between samples based on total identified peptide ion area.

\section{Gene ontology enrichment analysis}

gProfiler was used to undertake Gene Ontology (GO) enrichment analysis for the label-free mass spectrometry identified proteins with significant expression differences between each of the four experimental groups [36]. KEGG, Molecular Function (MF), Biological Process (BP) and Cellular Compartment (CC) enrichment analyses are generated by gProfiler are presented.

\section{Protein-protein interaction network analysis}

Differences in expression of proteins between groups were further analysed using the STRING database v.11.0 [37]. The platform was used to create proteinprotein interaction (PPI) networks based upon the differentially expressed proteins (DEPs) observed between groups.

\section{RESULTS AND DISCUSSION}

We subjected male Pink1 ${ }^{-}$and wild-type Drosophila to a seven-day exercise regimen, whilst maintaining groups of unexercised Pinkl $I^{-}$and wild-type as controls. The 
mitochondria of the four groups were then isolated and investigated using 2D gel electrophoresis and label-free mass spectrometry analyses to determine changes in their mitochondrial proteome. The 2D gel electrophoresis method allowed for a fast and simple separation of proteins, which served as a scoping method to identify some of the most significant changes in expression. Label-free mass spectrometry analyses generated proteomes that we used in network enrichment analysis. Previously we have used proteomic profiling to characterise mitochondrial populations in both mice and long-lived pipistrelle bats, and here we apply this to better understand the PD phenotype as well as possible changes due to exercise $[38,39]$.

\section{DE-MS identified a general reduction in protein expression post-exercise in the Pink1 mutant Drosophila}

We isolated mitochondria from exercised and nonexercised Pink1 Drosophila and performed 2DE-MS on these fractions (Supplementary Figure 1). All proteins that were identified as changed in expression after the exercise intervention were reduced in expression (Table 1). PINK1 is recognised as having a central role in mitophagy, ensuring a healthy pool of mitochondria are maintained $[19,20]$. It has recently been recognised that the regulation of mitophagy by the PINK1 system is age-dependent, with the Drosophila dependency on this pathway increasing with age [40]. Further, it has also been reported that earlier in the lifespan of the Drosophila there is a basal level of mitophagy that is not disrupted by the loss of PINK1 [41].

It is therefore possible that alternate mitophagy pathways can compensate for the loss of PINK1 and are upregulated during exercise, and this could account for the sweeping reductions in protein levels via 2DE-MS (Table 1). Indeed, alternative proteins have been identified and a pathway described in which they promote PINK1/PARKIN-independent mitophagy: AMBRA1, HUWE1 and IKK $\alpha$ [42]. It is also notable that ATG8, the final mediator of the AMBRA1 PINK1/PARKIN-independent mitophagy pathway, has been reported to be upregulated in response to exercise as a part of a broader upregulated autophagic response to exercise [43]. However, it could also be suggested that the energetic demands of the exercise result in less energy available to protein synthesis pathways. In this instance, exercise would likely affect proteostasis more broadly, beyond just the mitochondrial proteome.

The specific proteins identified within the table include structural proteins such as tropomyosin which is associated with the intracellular transport of mitochondria as well as mitochondrial metabolic proteins from a variety of pathways, such as acyl co-enzyme A dehydrogenase from the $\beta$-oxidation pathway, isocitrate dehydrogenase from the TCA cycle, and the metabolic gatekeeper pyruvate dehydrogenase. Due to the varied function of the proteins in Table 1, it is likely that their downregulation is representative of a broader decrease in protein expression levels in Pink1 Drosophila in response to exercise.

We proceeded to pursue the directionally homologous 2DE-MS results by obtaining a global topology of the mitochondrial protein changes that occur to Pink1Drosophila due to exercise intervention using a labelfree proteomics method.

\section{GO annotation of identified label-free proteins and proportion identified that are localised to mitochondria}

Non-gel-based label-free proteomic analyses identified 516 proteins from the mitochondrial fractions of Pink $1^{-}$ and wild-type Drosophila (Supplementary Table 1). GO and KEGG analyses showed that these fractions were enriched for mitochondrial processes and pathways, confirming the efficacy of our fractionation methodology (Figure 1). The top term of the GO cellular compartment analysis was cytoplasm, followed by mitochondrion and sub-mitochondrial compartments, many mitochondrial proteins are known to also localise to the cytoplasm $[44,45]$.

Pink1- Drosophila have decreased levels of proteins from energy metabolism pathways compared with wild-type Drosophila

Label-free proteomics highlighted 105 differently expressed proteins between non-exercised wild-type Drosophila and non-exercised Pinkl- Drosophila (Supplementary Table 2). Ten of the proteins were shown to be reduced in expression in Pink1- Drosophila compared to wild-type Drosophila. We found that Pink1- Drosophila have reductions in protein expression in proteins from mitochondrial processes associated with energy metabolism, with the top GO biological process terms being oxidative phosphorylation, electron transport chain, ATP metabolic process and oxidationreduction process (Figure 2).

The deficiencies in mitochondrial oxidative phosphorylation, the electron transport chain and specifically in the activity of Complex I in Parkinson's disease are well established, and this aligns with our findings from the $\mathrm{GO}$ analysis of the proteomics data [46-49]. Specific subunits of complexes within the electron transport chain that decreased in expression include $\mathrm{NADH}$ dehydrogenase (ubiquinone) $75 \mathrm{kDa}$ 
Table 1. Expression changes between exercised Pink1- Drosophila and non-exercised Pink1- Drosophila.

\begin{tabular}{lccc}
\hline Pink1 $\boldsymbol{I}^{-}$mitochondria - 2DE & & & \\
\hline Protein identity & ANOVA (p) & Fold change & Exercise related change \\
\hline Tropomyosin-1, isoforms 33/34 & 0.022 & 1.4 & $\downarrow$ \\
Tropomyosin-2 & 0.015 & 1.4 & $\downarrow$ \\
Acyl-coenzyme A dehydrogenase & 0.008 & 1.4 & $\downarrow$ \\
Isocitrate dehydrogenase & 0.022 & 1.3 & $\downarrow$ \\
Enolase & & & \\
Probable isocitrate dehydrogenase [NAD] subunit alpha & 0.015 & 1.5 & \\
Glycerol-3-phosphate dehydrogenase [NAD(+)] & & & \\
Pyruvate dehydrogenase E1 component subunit beta & 0.048 & 1.3 & $\downarrow$ \\
Pyruvate dehydrogenase E1 component subunit beta & & & \\
Aldo-keto reductase, isoform C & 0.024 & 1.3 & $\downarrow$ \\
Alcohol dehydrogenase & & \\
CG9992, isoform A & & \\
\hline
\end{tabular}

Changes in expression were determined by 2DE-MS.

subunit isoform B (complex I), GH01077p (complex III in Drosophila), HDC00331 (complex IV in Drosophila) and Levy isoform A (complex IV in Drosophila). While complex I and complex IV have been reported as dysfunctional in PD, reduced expression or decreased activity for complex III isn't well documented [47, 50, 51]. However, decreased Complex II/III activity has been shown in platelets of untreated Parkinson's disease patients [52].

It is interesting to note that most (95/105) of the differentially expressed proteins were more highly expressed in Pink1 Drosophila (Supplementary Table 2). GO biological process analysis showed these proteins to be enriched for redox processes, cytoplasmic translation, cellular amide metabolic processes and fatty acid derivative biosynthetic processes. GO cellular compartment analysis showed that the more highly expressed proteins in Pinkl $^{-}$were enriched for cytoplasmic ribosomes, organelle membranes and endoplasmic reticulum. KEGG pathway analysis paralleled these findings, highlighting the identified proteins as involved in fatty acid metabolism, ribosomes and one carbon pool by folate.

There is evidence linking fatty acid metabolism and function to Parkinson's disease, with proteins identified by GWAS studies, suppressed $\beta$-oxidation, and physical interaction between $\alpha$-synuclein and fatty acids potential being key factors [53-57]. Early studies into the effect of $\alpha$-synuclein $(S N C A)$ gene deletion on lipid metabolism in mice reported reduced palmate uptake and altered palmate metabolism in the brain, reduced acyl-CoA Synthetase activity that resulted in reduced arachidonic acid uptake and turnover, and increased docosahexaenoic acid brain mass, incorporation and turnover [58-60]. Our own work shows differences in arachidonic acid derivatives in Parkinson's disease mitochondria [61].

The data presented here show an enrichment of the folate metabolic pathway, not reported previously. It may be that in Pink1 Drosophila this is a compensatory mechanism. KEGG analysis highlighted the metabolism of folate (vitamin $\mathrm{B}_{9}$ ) as enriched in Pink1 Drosophila. B-vitamins, in particular folate, are well studied in the context of Parkinson's disease due to the observation of homocysteine (a methionine cycle metabolite) having neurotoxic effects [62-65]. It is hypothesised that the administration of B-vitamins can drive the synthesis of methionine, thus reducing intracellular homocysteine [66-68]. However, the relationship between B vitamins, neurotoxicity and Parkinson's disease is complex and a consensus has yet to be established. Some data show either little correlation between homocysteine levels and B vitamins including B6, folate and B12 while others show contradictory results, including elevated homocysteine levels and decreased folate levels in Parkinson's disease patients [68-71].

\section{Exercise reduces measured protein levels in Pink1 Drosophila}

The 2DE-MS analysis of exercised and non-exercised Pink $1^{-}$Drosophila revealed reductions in twelve proteins in response to exercise (Table 1). Label-free proteomics showed a similar pattern in Pink ${ }^{l-}$ exercised Drosophila compared with non-exercised Pinkl- Drosophila; of the fifty-seven protein expression differences, fifty-five were reductions of protein expression in response to 


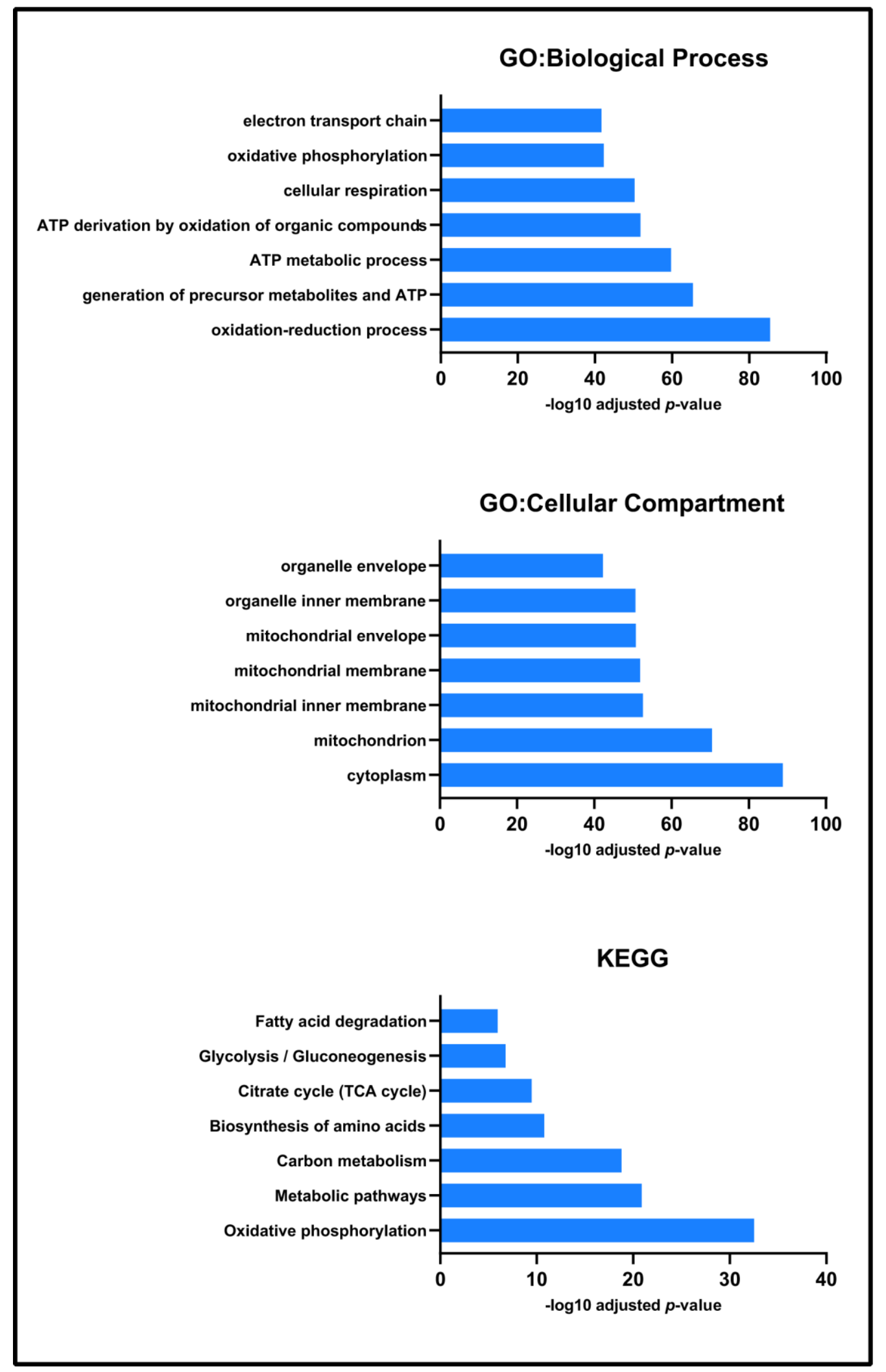

Figure 1. Enrichment analysis of all proteins identified by label-free proteomics. Biological process, cellular compartment and KEGG enrichment analysis each presented processes associated with mitochondrial function and physiology. 
exercise (Supplementary Table 3). GO:MF and KEGG pathway analysis determined that the terms ribosomal and fatty acid metabolism were significantly represented in the proteins with reduced expression (Figure 3). Interestingly, these terms were shown to be increased in Pink1 Drosophila compared to wild-type Drosophila that had not been exercised. This suggests that in Pink1 Drosophila exercise returns levels of protein expression towards wild-type values.

It has been shown that PINK1 interacts with the protein translation pathway and that increased protein translation in Pink $1^{-}$Drosophila causes an exacerbated Pink $1^{-}$phenotype. Taking this a step further, it was shown that $40 \mathrm{~S}$ ribosomal subunit S6 (RpS6) RNAi was able to mitigate the Pink1phenotype [72]. These data suggest improper protein translation regulation is involved in the pathogenesis of PD and that inhibition of this pathway mitigates progression. Exercise appears to be able to reverse the upregulated protein translation pathways found in Pink1- Drosophila.

KEGG analysis identified fatty acid metabolism from proteins reduced in expression due to exercise, while GO:MF analysis highlighted CoA Carboxylase activity from the same protein data set. This reduction in the metabolism, and in particular the synthesis, of fatty acids can be contrasted with the KEGG analysis described earlier which identified elevated expression of fatty acid metabolism associated proteins in Pink ${ }^{-}$ Drosophila compared with wild-type Drosophila. It can be interpreted that exercise reverses the change in
Pink1 Drosophila and returns the fatty acid metabolic profile back towards wild-type Drosophila.

The two proteins upregulated with exercise in Pink - $^{-}$ Drosophila were OCIA domain-containing protein 1 (OCIAD1) and dihydroorotate dehydrogenase (quinone) mitochondrial (DHODH), neither have previously been connected with exercise. OCIAD1 has been shown to localise to both endosomes and mitochondria and regulate pathways such as JAK/STAT, Notch and PI3K/AKT [73-75]. OCIAD1 has been shown to regulate mitochondrial ETC activity via control of complex I activity, which showed an inverse association with OCIAD1 overexpression [76]. Deregulated OCIAD1 levels have been linked to mitochondrial dysfunction, interaction with BCL-2 and Alzheimer's disease [75].

DHODH is an inner mitochondrial membrane enzyme that catalyses the fourth step in de novo synthesis of pyrimidines [77]. A link between pyrimidine synthesis and mitochondrial morphology was shown with the addition of the drug leflunomide to muscle cells [78]. The group showed that leflunomide inhibited DHODH by binding to its ubiquinone binding channel, thereby preventing the production of pyrimidine ribonucleotide uridine monophosphate (UMP). DHODH inhibition induced upregulation of mitochondrial fusion and subsequent mitochondrial elongation, by depleting the cellular pyrimidine pool. As ubiquinone is reduced to ubiquinol in the DHODH-mediated catalysis of dihydroorotate to orotate, and as ubiquinol is a substrate of respiratory complex III, DHODH is important for the

\section{GO:Biological Process}

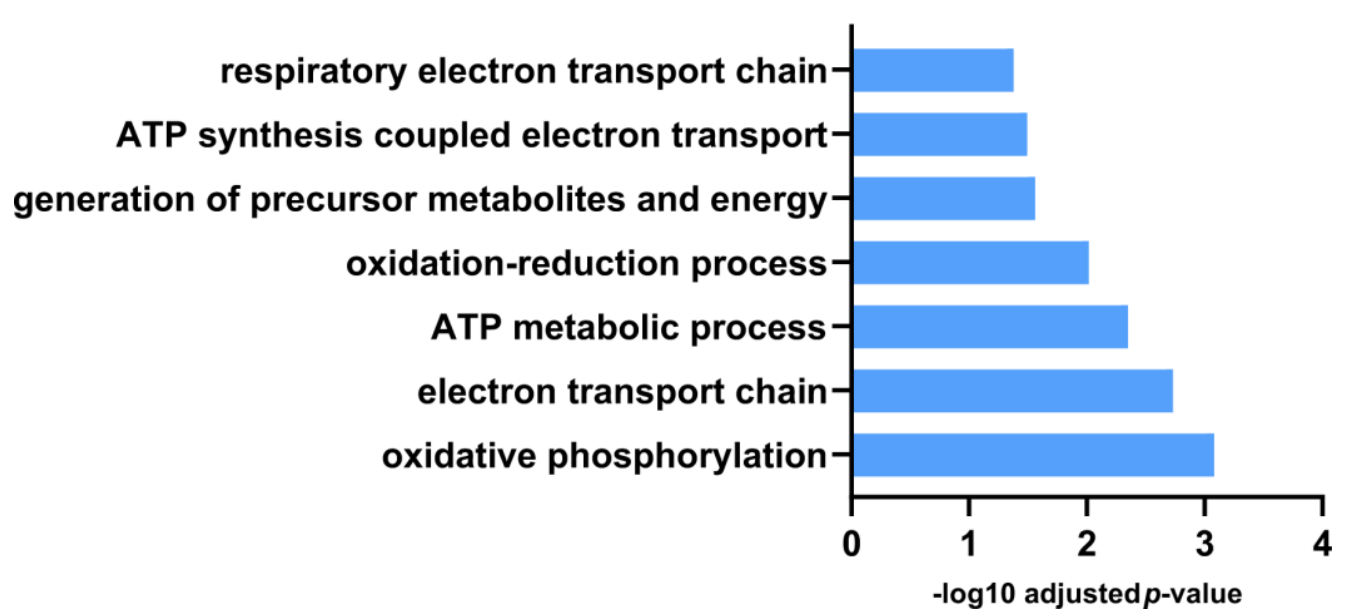

Figure 2. GO: Biological process analysis for downregulated protein expression differences between Pink1 non-exercised and wild-type non-exercised files. Pink1 files have reduced expression of proteins involved in mitochondrial respiration and oxidative phosphorylation. 
ETS. DHODH deficiency has been reported to partially inhibit complex III and increase ROS generation [79].

The same Pink1 Drosophila strain has previously been reported to have upregulated genes involved in nucleotide metabolism, which is also the case in brains of
PD patients with PINK1 mutations [80]. Genetic and pharmacological upregulation of nucleotide metabolism and scavenging pathways restored mitochondrial function caused by PINK1 loss. Therefore, DHODH upregulation by exercise may act in a compensatory manner to manage metabolic stress due to the Pinkl' phenotype.

ligase activity, forming carbon-carbon bonds steroid dehydrogenase activity
steroid dehydrogenase activity,
acting on the CH-OH group of donors,
NAD or NADP as acceptor
CoA carboxylase activity catalytic activity structural constituent of ribosome

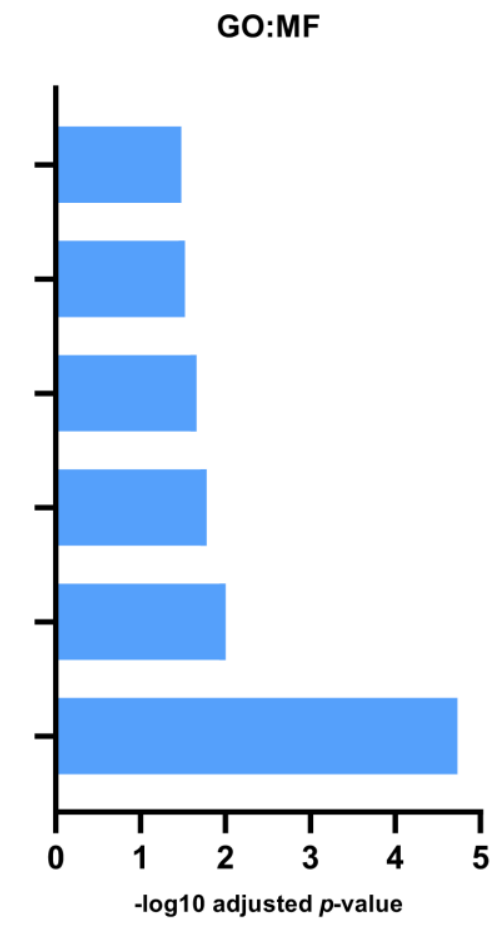

KEGG

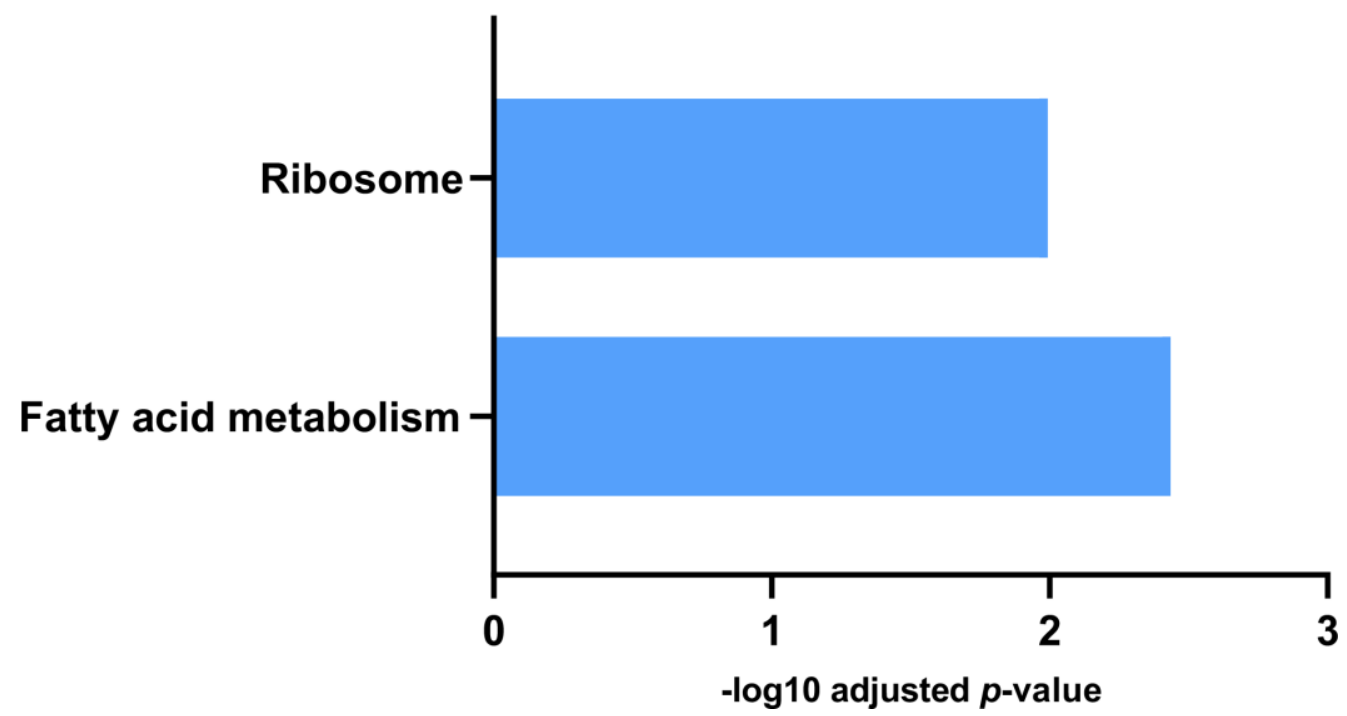

Figure 3. GO: Molecular Function and KEGG analysis for proteins reduced in expression in Pink1- exercised files compared with Pink1- non-exercised files. Both Molecular Function and KEGG enrichment analysis indicated a decrease in expression of fatty acid metabolic proteins in the exercised Pink1- files. 


\section{Exercise reduces the difference in levels of protein expression between Pink1- and wild-type drosophila}

Of the 516 proteins identified, 105 protein had different levels between non-exercised Pink1 Drosophila and non-exercised wild-type Drosophila (Supplementary Table 2). Comparing the exercised Pink1- Drosophila group to either non-exercised wild-type Drosophila, or exercised wild-type Drosophila, showed close to half the number of differentially expressed proteins (55 and 56 proteins, respectively) (Supplementary Tables 4, 5). Qualitatively the heatmap of protein expression for exercised Pink ${ }^{-}$Drosophila more closely resembles wild-type Drosophila (Figure 4). This suggests exercise can ameliorate the aberrant protein profile of Pink ${ }^{-}$ Drosophila towards a more wild-type profile.

This is in agreement with findings from Cheedipudi et al. (2020) who reported gene expression data from an exercised mouse model of arrhythmogenic cardiomyopathy, that originally showed a dysregulation of near 800 genes, showed partial restoration of gene expression with regular exercise, with the greatest remedial effects on proteins involved in inflammation and oxidative phosphorylation [81].

\section{Network analyses of differentially expressed proteins}

STRING database network analysis complemented the results seen with gProfiler. The protein-protein interaction (PPI) networks were generated using STRING, and Figure 5A shows that exercised Pink1Drosophila, compared with the exercised wild-type Drosophila, have a differentially expressed proteins (DEPs) network that consisted of 49 nodes and 200 edges with average node degree 8.16 and PPI enrichment $\mathrm{p}$-value of $(\mathrm{P}<1.0 \mathrm{e}-16)$.

Most of the proteins in the network have downregulated expression, with the following proteins found to be upregulated: endoplasmic reticulum chaperone $\mathrm{BiP}$, enoyl-CoA hydratase short chain, glutamine synthetase, protein disulfide isomerase, methylmalonatesemialdehyde dehydrogenase, polyadenylate-binding protein, poly(U)-specific endoribonuclease, glutamine synthetase, flotillin-1, heat shock protein 22, phosphatidate cytidylyltransferase, fatty acyl-CoA reductase and dihydroorotate dehydrogenase.

The DEPs were found to be part of the ETC and OXPHOS processes, transmembrane transport and oxidative-reduction processes. The highly connected cluster in this network consisted of proteins from complex I: ND-18, ND-MLRQ, ND-ASHI, NDB14.5B, ND-B14, ND-B16.6, ND-49, ND-51, NDB17.2, ND-B14.7; complex IV: COX6B, COX4, mt:
COII, COX5A; complex III: OX, and other proteins CYPE, UQCR-6.4, UQCR-14, levy and 40S ribosomal proteins S18. This cluster of proteins was downregulated in the exercised Pink1' Drosophila.

Figure 5B shows the non-exercised Pink1- Drosophila versus the non-exercised wild-type Drosophila PPI network, which consists of 86 nodes and 121 edges with average node degree 2.81 and PPI enrichment p-value (P $<1.0 \mathrm{e}-16)$. In contrast to exercised Pink1 ${ }^{-}$Drosophila versus exercised wild-type Drosophila, all DEPs were upregulated, except for cytochrome c oxidase subunit 4, cyclope isoform $\mathrm{A}$, flightin isoform $\mathrm{B}$, cytochrome $\mathrm{b}-\mathrm{c} 1$ complex subunit 7, NADH dehydrogenase 1 alpha subcomplex 12, Troponin 1, NADH dehydrogenase 18, cytochrome c oxidase subunit, cytochrome P450, NADH dehydrogenase 1 beta subcomplex subunit 8 , cytochrome $\mathrm{c}$ oxidase subunit 5A, NADH dehydrogenase B14 and levy isoform A.

The DEPs were found to be a part of oxidation-reduction processes, fatty-acyl-CoA metabolic processes, translation and protein folding. The identification of DEPs from fatty-acyl-CoA metabolic process is concurrent with the enrichment analysis presented in Figure 3 . The highly connected node in this network is that of upregulated ribosomal proteins RPS18, RPS23, RPS23, RPS7, RPS14b, RPL6, RPL5, RPL10AB and RPL9.

The DEPs were found to be a part of oxidation-reduction processes, fatty-acyl-CoA metabolic processes, translation and protein folding. The identification of DEPs from fatty-acyl-CoA metabolic process concurs with the enrichment analysis presented in Figure 3. The highly connected node in this network is that of upregulated ribosomal proteins RPS18, RPS23, RPS23, RPS7, RPS14b, RPL6, RPL5, RPL10AB and RPL9.

Similarly, for Figure 6A-6C, three additional PPI networks were generated for DEPs in pairwise group comparisons. For exercised Pink1- Drosophila compared with non-exercised Pink1- Drosophila the PPI network consisted of 43 nodes and 29 edges with average node degree 1.35 and PPI enrichment $p$-value $<1.62 \mathrm{e}-06$ (Figure 6A). All of the DEPs were downregulated except for OCIA domain containing protein 1 and dihydroorotate dehydrogenase. The DEPs were found to be involved in formation of $40 \mathrm{~S}$ ribosomal subunit, oxidation reduction processes, synthesis of ketone bodies, translation and cellular lipid catabolic processes.

For non-exercised Pink1- Drosophila compared with exercised wild-type Drosophila the network has 107 
nodes and 341 edges with average node degree 6.37 and PPI enrichment $\mathrm{p}$-value (P <1.0e-16) (Figure 6B). The DEPs were found to be involved in ETC, translation, peroxisome, formation of $40 \mathrm{~S}$ subunits and protein folding. The PPI network showed three highly connected clusters. Cluster 1 contained proteins from both complex I and complex IV, proteins that are downregulated like that of exercised Pink1 ${ }^{-}$Drosophila compared with the exercised wild-type Drosophila. Cluster 2 contained ribosomal proteins that are upregulated, similar to that of non-exercised Pink1 Drosophila compared with the non-exercised wild-type Drosophila PPI network. Cluster 3 contains the proteins
UGT, HSP22, HSP60C, CABP1, GP93, HSC70-5, HSC70Cb, HSP60A, RTNL1 and CNX99A. These proteins involved in proteostasis and protein folding and were found to be upregulated.

For the final PPI network, exercised Pink1- Drosophila compared with non-exercised wild-type Drosophila, there are 44 nodes and 40 edges with average node degree 1.82 and PPI enrichment p-value 6.79e-11 (Figure 6C). The exercised Pinkl- Drosophila versus non-exercised wild-type Drosophila were involved in purine ribonucleotide triphosphate metabolic processes, ETC and peroxisomes.

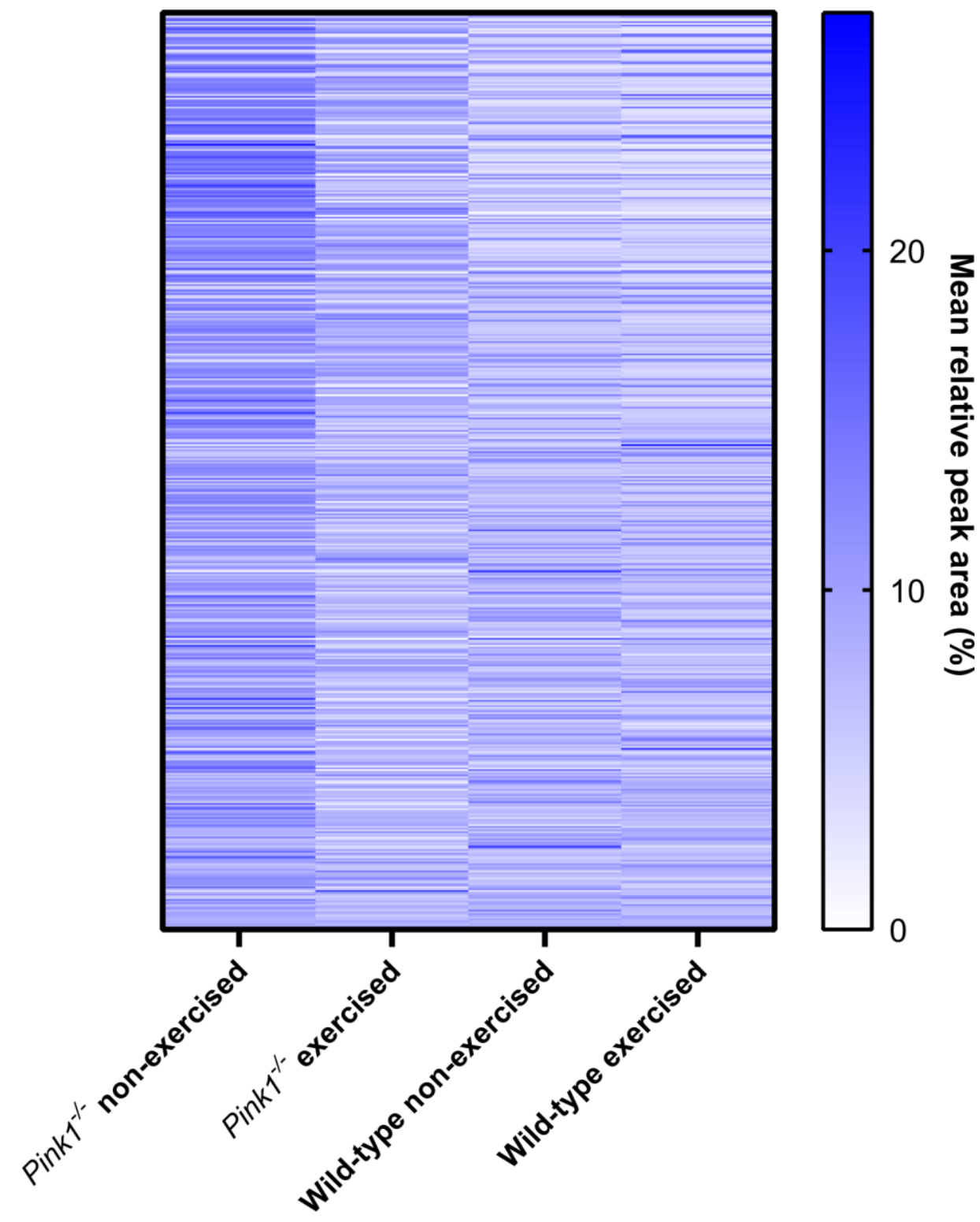

Figure 4. Heat map of protein expression levels (for proteins identified among all groups), determined by label-free mass spectrometry of mitochondrial fractions. Qualitatively, the identified Pink1- exercised fly proteome more closely resembles the two WT fly proteomes than does the Pink1 non-exercised fly proteome. 
A PINK1-ex vs wildtype-ex

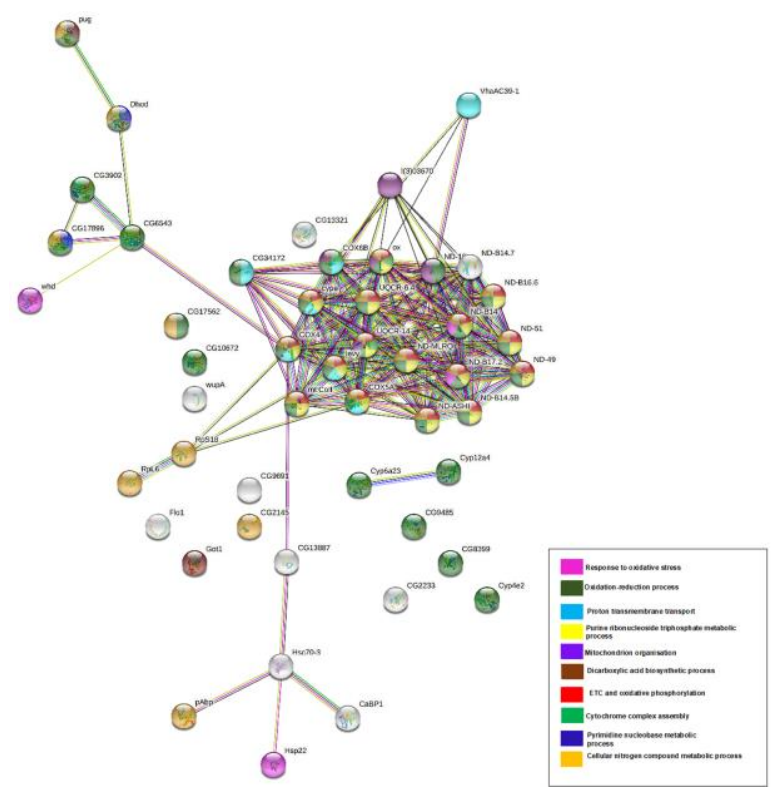

B PINK1-nex vs wildtype-nex

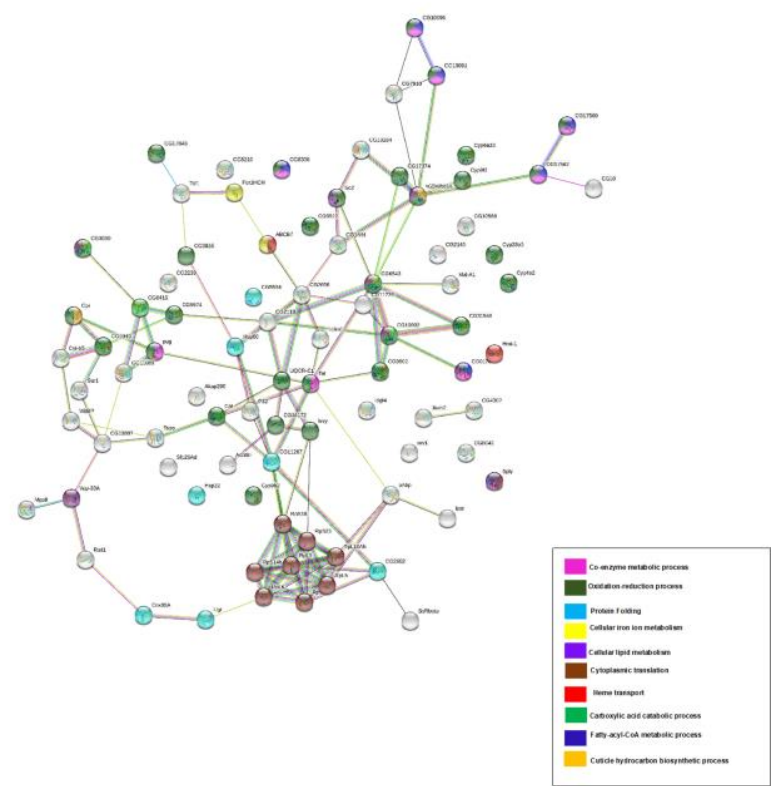

Figure 5. Network analysis of differentially expressed proteins. (A) Pink1- exercised vs wild type exercised; (B) Pink1- non-exercised vs wild type non-exercised. Networks analysed using STRINGdb. The nodes are coloured according to the processes (legend) that the proteins are involved in by using GO Terms for Biological Processes. The edge shows type of interactions, experimentally determined interactions are pink and those obtained from databases are sky blue. Predicted interactions such as gene neighbourhood are blue, green and red for gene co-occurrence, gene neighbourhood and gene fusions. Co-expression interactions are shown in black, text-mining interactions are shown in light green and protein homology edges are purple.
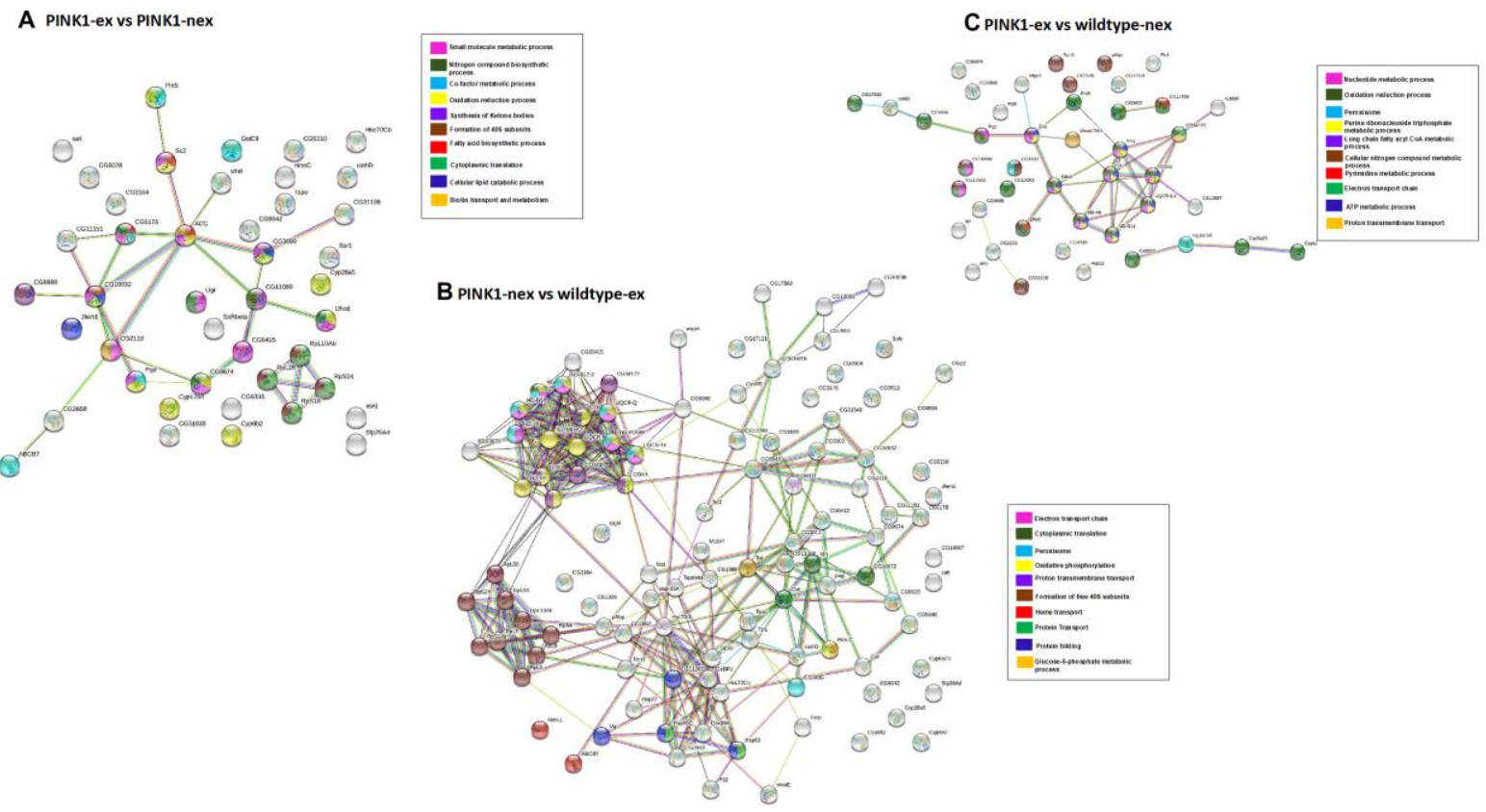

Figure 6. Network analysis of differentially expressed proteins. (A) Pink1- exercised vs Pink1- non-exercised; (B) Pink1- non-exercised vs wild type exercised; (C) Pink1- exercised vs wild type non-exercised. Networks analysed using STRINGdb. The nodes are coloured according to the processes (legend) that the proteins are involved in by using GO Terms for Biological Processes. The edge shows type of interactions, experimentally determined interactions are pink and the one obtained from databases are sky blue. Predicted interactions such as gene neighbourhood are blue, green and red for gene co-occurrence, gene neighbourhood and gene fusions. Co-expression interactions are shown in black, text-mining interactions are shown in light green and protein homology edges are purple. 
For each of the three PPI networks, the number of edges is larger than expected and the nodes were more connected than for a random PPI network of the same size.

\section{CONCLUSIONS}

A picture of mitochondrial proteomic changes made in response to exercise was obtained by using two different mass spectrometry methodologies. We were able to measure changes in an organelle whose function in exercise, and dysfunction in Parkinson's disease, is crucial.

2D-GE MS data comparison between Pink $1^{-}$exercised and Pink $1^{-}$non-exercised Drosophila revealed several proteins with decreased levels of expression in response to exercise. These data were indicative of a generalised reduction of expression of the mitochondrial proteome in Pink1 $1^{-}$Drosophila in response to exercise. This was investigated further in exercised and non-exercised Drosophila, both wild-type and Pink1-, by label-free mass spectrometry.

GO and KEGG analyses of the label-free mass spectrometry proteomic data validated our mitochondrial isolation methodology by identifying the enrichment of mitochondrial processes and pathways. The comparison between non-exercised wild-type Drosophila and nonexercised Pink1 Drosophila revealed that proteins involved in bioenergetics had reduced expression in the mutant. Most strikingly, exercise of the Pink1 Drosophila caused a broad reduction in protein expression within the mitochondrial protein, resulting in the Pink1 Drosophila mitochondrial proteome to return to levels similar to the wild-type Drosophila.

GO, KEGG and STRING network analysis of the differentially expressed proteins from the mitochondrial proteome comparisons identified enrichment of bioenergetic pathways. The most significantly enriched pathways in the non-exercised Pinkl Drosophila included oxidation-reduction, fatty acid metabolism, and folate metabolism, all of which are associated with PD. Our data point to exercise aiding normalisation of these pathways. Specific proteins in the pathways may be candidates to develop therapeutic approaches in PD.

\section{AUTHOR CONTRIBUTIONS}

BE performed data analysis, assisted with experiments, and wrote the manuscript, TLI performed experimental work and helped prepare the manuscript, GK performed STRING analyses and helped prepare the manuscript, JRI developed and constructed the ICE machine for fly exercise, NM generated the Drosophila used for these experiments and was consulted on all aspects of the fly work, LC directed the research, supervised experiments, provided reagents and prepared the manuscript.

\section{CONFLICTS OF INTEREST}

The authors declare that they have no conflicts of interest.

\section{FUNDING}

This work was supported by the Biotechnology and Biological Sciences Research Council [grant number $\mathrm{BB} / \mathrm{J} 014508 / 1]$, via awards to $\mathrm{BE}$ and TLI. GK is supported by a University of Nottingham ViceChancellors International Scholarship award. NM and LC are funded by HEFCE.

\section{REFERENCES}

1. GBD 2016 Parkinson's Disease Collaborators. Global, regional, and national burden of Parkinson's disease, 1990-2016: a systematic analysis for the Global Burden of Disease Study 2016. Lancet Neurol. 2018; 17: 939-53.

https://doi.org/10.1016/S1474-4422(18)30295-3 PMID:30287051

2. Storey A. Living longer - how our population is changing and why it matters. Off. Natl. Stat. 2018; 1-53.

3. Hirsch E, Graybiel AM, Agid YA. Melanized dopaminergic neurons are differentially susceptible to degeneration in Parkinson's disease. Nature. 1988; 334:345-48.

https://doi.org/10.1038/334345a0 PMID:2899295

4. Schulz-Schaeffer WJ. The synaptic pathology of alphasynuclein aggregation in dementia with Lewy bodies, Parkinson's disease and Parkinson's disease dementia. Acta Neuropathol. 2010; 120:131-43. https://doi.org/10.1007/s00401-010-0711-0 PMID:20563819

5. Park JS, Davis RL, Sue CM. Mitochondrial Dysfunction in Parkinson's Disease: New Mechanistic Insights and Therapeutic Perspectives. Curr Neurol Neurosci Rep. 2018; 18:21.

https://doi.org/10.1007/s11910-018-0829-3 PMID:29616350

6. Alegre-Abarrategui J, Christian $\mathrm{H}$, Lufino MM, Mutihac $\mathrm{R}$, Venda LL, Ansorge O, Wade-Martins R. LRRK2 regulates autophagic activity and localizes to specific membrane microdomains in a novel human genomic reporter cellular model. Hum Mol Genet. 2009; 18:4022-34. 
https://doi.org/10.1093/hmg/ddp346

PMID:19640926

7. Thomas KJ, McCoy MK, Blackinton J, Beilina A, van der Brug $M$, Sandebring A, Miller D, Maric D, CedazoMinguez A, Cookson MR. DJ-1 acts in parallel to the PINK1/parkin pathway to control mitochondrial function and autophagy. Hum Mol Genet. 2011; 20:40-50.

https://doi.org/10.1093/hmg/ddq430 PMID:20940149

8. Zavodszky E, Seaman MN, Moreau K, Jimenez-Sanchez M, Breusegem SY, Harbour ME, Rubinsztein DC. Mutation in VPS35 associated with Parkinson's disease impairs WASH complex association and inhibits autophagy. Nat Commun. 2014; 5:3828.

https://doi.org/10.1038/ncomms4828 PMID:24819384

9. Palikaras K, Lionaki E, Tavernarakis N. Mechanisms of mitophagy in cellular homeostasis, physiology and pathology. Nat Cell Biol. 2018; 20:1013-22.

https://doi.org/10.1038/s41556-018-0176-2

PMID:30154567

10. Shiba-Fukushima K, Imai Y, Yoshida S, Ishihama $Y$, Kanao T, Sato S, Hattori N. PINK1-mediated phosphorylation of the Parkin ubiquitin-like domain primes mitochondrial translocation of Parkin and regulates mitophagy. Sci Rep. 2012; 2:1002. https://doi.org/10.1038/srep01002 PMID:23256036

11. Kondapalli C, Kazlauskaite A, Zhang N, Woodroof HI, Campbell DG, Gourlay R, Burchell L, Walden $\mathrm{H}$, Macartney TJ, Deak M, Knebel A, Alessi DR, Muqit MM. PINK1 is activated by mitochondrial membrane potential depolarization and stimulates Parkin E3 ligase activity by phosphorylating Serine 65. Open Biol. 2012; 2:120080.

https://doi.org/10.1098/rsob.120080 PMID:22724072

12. Koyano F, Okatsu K, Kosako H, Tamura Y, Go E, Kimura $M$, Kimura $Y$, Tsuchiya $H$, Yoshihara $H$, Hirokawa $T$, Endo T, Fon EA, Trempe JF, et al. Ubiquitin is phosphorylated by PINK1 to activate parkin. Nature. 2014; 510:162-66.

https://doi.org/10.1038/nature13392 PMID:24784582

13. Kazlauskaite A, Kondapalli C, Gourlay R, Campbell DG, Ritorto MS, Hofmann K, Alessi DR, Knebel A, Trost M, Muqit MM. Parkin is activated by PINK1-dependent phosphorylation of ubiquitin at Ser65. Biochem J. 2014; 460:127-39.

https://doi.org/10.1042/BJ20140334

PMID:24660806

14. Ordureau A, Sarraf SA, Duda DM, Heo JM, Jedrychowski MP, Sviderskiy VO, Olszewski JL, Koerber JT, Xie T, Beausoleil SA, Wells JA, Gygi SP, Schulman BA, Harper JW. Quantitative proteomics reveal a feedforward mechanism for mitochondrial PARKIN translocation and ubiquitin chain synthesis. Mol Cell. 2014; 56:360-75.

https://doi.org/10.1016/j.molcel.2014.09.007

PMID:25284222

15. Cookson MR. Parkinsonism due to mutations in PINK1, parkin, and DJ-1 and oxidative stress and mitochondrial pathways. Cold Spring Harb Perspect Med. 2012; 2:a009415.

https://doi.org/10.1101/cshperspect.a009415 PMID:22951446

16. Pankratz N, Foroud T. Genetics of Parkinson disease. Genet Med. 2007; 9:801-11. https://doi.org/10.1097/gim.0b013e31815bf97c PMID:18091429

17. Sliter DA, Martinez J, Hao L, Chen X, Sun N, Fischer TD, Burman JL, Li Y, Zhang Z, Narendra DP, Cai H, Borsche M, Klein C, Youle RJ. Parkin and PINK1 mitigate STINGinduced inflammation. Nature. 2018; 561:258-62. https://doi.org/10.1038/s41586-018-0448-9 PMID:30135585

18. Zhong Z, Liang S, Sanchez-Lopez E, He F, Shalapour S, Lin XJ, Wong J, Ding S, Seki E, Schnabl B, Hevener AL, Greenberg HB, Kisseleva $T$, Karin $M$. New mitochondrial DNA synthesis enables NLRP3 inflammasome activation. Nature. 2018; 560:198-203. https://doi.org/10.1038/s41586-018-0372-z PMID:30046112

19. Park J, Lee SB, Lee S, Kim Y, Song S, Kim S, Bae E, Kim J, Shong M, Kim JM, Chung J. Mitochondrial dysfunction in Drosophila PINK1 mutants is complemented by parkin. Nature. 2006; 441:1157-61. https://doi.org/10.1038/nature04788 PMID:16672980

20. Clark IE, Dodson MW, Jiang C, Cao JH, Huh JR, Seol JH, Yoo SJ, Hay BA, Guo M. Drosophila pink1 is required for mitochondrial function and interacts genetically with parkin. Nature. 2006; 441:1162-66.

https://doi.org/10.1038/nature04779 PMID:16672981

21. Greene JC, Whitworth AJ, Kuo I, Andrews LA, Feany $M B$, Pallanck LJ. Mitochondrial pathology and apoptotic muscle degeneration in Drosophila parkin mutants. Proc Natl Acad Sci USA. 2003; 100:4078-83.

https://doi.org/10.1073/pnas.0737556100 PMID:12642658

22. Pickrell AM, Youle RJ. The roles of PINK1, parkin, and mitochondrial fidelity in Parkinson's disease. Neuron. 2015; 85:257-73.

https://doi.org/10.1016/j.neuron.2014.12.007 PMID:25611507

23. Morais VA, Verstreken $P$, Roethig A, Smet J, Snellinx A, Vanbrabant M, Haddad D, Frezza C, Mandemakers W, Vogt-Weisenhorn D, Van Coster R, Wurst W, Scorrano L, De Strooper B. Parkinson's disease mutations in 
PINK1 result in decreased Complex I activity and deficient synaptic function. EMBO Mol Med. 2009; 1:99-111.

https://doi.org/10.1002/emmm.200900006

PMID:20049710

24. Liu W, Acín-Peréz R, Geghman KD, Manfredi G, Lu B, Li C. Pink1 regulates the oxidative phosphorylation machinery via mitochondrial fission. Proc Natl Acad Sci USA. 2011; 108:12920-24.

https://doi.org/10.1073/pnas.1107332108

PMID:21768365

25. Julienne H, Buhl E, Leslie DS, Hodge JJ. Drosophila PINK1 and parkin loss-of-function mutants display a range of non-motor Parkinson's disease phenotypes. Neurobiol Dis. 2017; 104:15-23.

https://doi.org/10.1016/j.nbd.2017.04.014

PMID:28435104

26. Sasco AJ, Paffenbarger RS Jr, Gendre I, Wing AL. The role of physical exercise in the occurrence of Parkinson's disease. Arch Neurol. 1992; 49:360-65. https://doi.org/10.1001/archneur.1992.005302800400 20 PMID: 1558515

27. Yang F, Trolle Lagerros $Y$, Bellocco R, Adami HO, Fang F, Pedersen NL, Wirdefeldt K. Physical activity and risk of Parkinson's disease in the Swedish National March Cohort. Brain. 2015; 138:269-75.

https://doi.org/10.1093/brain/awu323

PMID:25410713

28. Ashburn A, Fazakarley L, Ballinger C, Pickering R, McLellan LD, Fitton C. A randomised controlled trial of a home based exercise programme to reduce the risk of falling among people with Parkinson's disease. J Neurol Neurosurg Psychiatry. 2007; 78:678-84.

https://doi.org/10.1136/innp.2006.099333 PMID:17119004

29. Goodwin VA, Richards SH, Taylor RS, Taylor AH, Campbell JL. The effectiveness of exercise interventions for people with Parkinson's disease: a systematic review and meta-analysis. Mov Disord. 2008; 23:631-40.

https://doi.org/10.1002/mds.21922 PMID:18181210

30. Murray DK, Sacheli MA, Eng JJ, Stoessl AJ. The effects of exercise on cognition in Parkinson's disease: a systematic review. Transl Neurodegener. 2014; 3:5.

https://doi.org/10.1186/2047-9158-3-5

PMID:24559472

31. Shin MS, Jeong HY, An DI, Lee HY, Sung YH. Treadmill exercise facilitates synaptic plasticity on dopaminergic neurons and fibers in the mouse model with Parkinson's disease. Neurosci Lett. 2016; 621:28-33. https://doi.org/10.1016/i.neulet.2016.04.015 PMID:27080424
32. Jang $\mathrm{Y}$, Koo JH, Kwon I, Kang EB, Um HS, Soya H, Lee $\mathrm{Y}$, Cho JY. Neuroprotective effects of endurance exercise against neuroinflammation in MPTP-induced Parkinson's disease mice. Brain Res. 2017; 1655: 186-93.

https://doi.org/10.1016/i.brainres.2016.10.029 PMID:27816415

33. Klemann CJ, Xicoy H, Poelmans G, Bloem BR, Martens GJ, Visser JE. Physical Exercise Modulates L-DOPARegulated Molecular Pathways in the MPTP Mouse Model of Parkinson's Disease. Mol Neurobiol. 2018; 55:5639-57.

https://doi.org/10.1007/s12035-017-0775-0 PMID:29019056

34. Life Technologies. ZOOM ${ }^{\circledR}$ IPGRunner TM System For isoelectric focusing of ZOOM ${ }^{\circledR}$ Strips Catalog Numbers ZM0001, ZM0002, ZM0004. 2012.

35. Centre for Excellence in Mass Spectrometry. FAQs Biology, The University of York. 2019.

36. Raudvere U, Kolberg L, Kuzmin I, Arak T, Adler P, Peterson H, Vilo J. g:Profiler: a web server for functional enrichment analysis and conversions of gene lists (2019 update). Nucleic Acids Res. 2019; 47:W191-98.

https://doi.org/10.1093/nar/gkz369 PMID:31066453

37. Szklarczyk D, Gable AL, Lyon D, Junge A, Wyder S, Huerta-Cepas J, Simonovic M, Doncheva NT, Morris JH, Bork P, Jensen $\sqcup$, Mering CV. STRING v11: proteinprotein association networks with increased coverage, supporting functional discovery in genome-wide experimental datasets. Nucleic Acids Res. 2019; 47:D607-13.

https://doi.org/10.1093/nar/gky1131 PMID:30476243

38. Pollard A, Shephard F, Freed J, Liddell S, Chakrabarti L. Mitochondrial proteomic profiling reveals increased carbonic anhydrase II in aging and neurodegeneration. Aging (Albany NY). 2016; 8:2425-36.

https://doi.org/10.18632/aging.101064 PMID:27743511

39. Pollard AK, Ingram TL, Ortori CA, Shephard F, Brown M, Liddell S, Barrett DA, Chakrabarti L. A comparison of the mitochondrial proteome and lipidome in the mouse and long-lived Pipistrelle bats. Aging (Albany NY). 2019; 11:1664-85.

https://doi.org/10.18632/aging.101861 PMID: $\underline{0892277}$

40. Cornelissen T, Vilain S, Vints K, Gounko N, Verstreken $P$, Vandenberghe W. Deficiency of parkin and PINK1 impairs age-dependent mitophagy in Drosophila. Elife. 2018; 7:e35878.

https://doi.org/10.7554/eLife.35878

PMID:29809156 
41. Lee JJ, Sanchez-Martinez A, Martinez Zarate A, Benincá C, Mayor U, Clague MJ, Whitworth AJ. Basal mitophagy is widespread in Drosophila but minimally affected by loss of Pink1 or parkin. J Cell Biol. 2018; 217:1613-22. https://doi.org/10.1083/jcb.201801044 PMID:29500189

42. Di Rita A, Peschiaroli A, D Acunzo P, Strobbe D, Hu Z, Gruber J, Nygaard M, Lambrughi M, Melino G, Papaleo E, Dengjel J, El Alaoui S, Campanella M, et al. HUWE1 E3 ligase promotes PINK1/PARKIN-independent mitophagy by regulating AMBRA1 activation via IKK $\alpha$. Nat Commun. 2018; 9:3755.

https://doi.org/10.1038/s41467-018-05722-3 PMID:30217973

43. Lira VA, Okutsu $M$, Zhang $M$, Greene NP, Laker RC, Breen DS, Hoehn KL, Yan Z. Autophagy is required for exercise training-induced skeletal muscle adaptation and improvement of physical performance. FASEB J. 2013; 27:4184-93.

https://doi.org/10.1096/fj.13-228486 PMID:23825228

44. Yogev O, Pines O. Dual targeting of mitochondrial proteins: mechanism, regulation and function. Biochim Biophys Acta. 2011; 1808:1012-20.

https://doi.org/10.1016/j.bbamem.2010.07.004 PMID:20637721

45. Ben-Menachem R, Tal M, Shadur T, Pines O. A third of the yeast mitochondrial proteome is dual localized: a question of evolution. Proteomics. 2011; 11:4468-76. https://doi.org/10.1002/pmic.201100199 PMID:21910249

46. Parker WD Jr, Boyson SJ, Parks JK. Abnormalities of the electron transport chain in idiopathic Parkinson's disease. Ann Neurol. 1989; 26:719-23. https://doi.org/10.1002/ana.410260606 PMID:2557792

47. Schapira AH, Cooper JM, Dexter D, Clark JB, Jenner P, Marsden CD. Mitochondrial complex I deficiency in Parkinson's disease. J Neurochem. 1990; 54:823-27. https://doi.org/10.1111/i.1471-4159.1990.tb02325.x PMID:2154550

48. Shoffner JM, Watts RL, Juncos JL, Torroni A, Wallace DC. Mitochondrial oxidative phosphorylation defects in Parkinson's disease. Ann Neurol. 1991; 30:332-39.

https://doi.org/10.1002/ana.410300304

PMID:1952821

49. Finsterer J, Jarius C, Baumgartner M. Parkinson's disease associated with impaired oxidative phosphorylation. Neuroradiology. 2001; 43:997-1000. https://doi.org/10.1007/s002340100618 PMID:11760809

50. Keeney PM, Xie J, Capaldi RA, Bennett JP Jr. Parkinson's disease brain mitochondrial complex I has oxidatively damaged subunits and is functionally impaired and misassembled. J Neurosci. 2006; 26:5256-64. https://doi.org/10.1523/JNEUROSCI.0984-06.2006 PMID: $\underline{16687518}$

51. Müftüoglu M, Elibol B, Dalmizrak O, Ercan A, Kulaksiz G, Ogüs H, Dalkara T, Ozer N. Mitochondrial complex I and IV activities in leukocytes from patients with parkin mutations. Mov Disord. 2004; 19:544-48. https://doi.org/10.1002/mds.10695 PMID:15133818

52. Haas RH, Nasirian F, Nakano K, Ward D, Pay M, Hill R, Shults CW. Low platelet mitochondrial complex I and complex II/III activity in early untreated Parkinson's disease. Ann Neurol. 1995; 37:714-22. https://doi.org/10.1002/ana.410370604 PMID:7778844

53. Chang D, Nalls MA, Hallgrímsdóttir IB, Hunkapiller J, van der Brug M, Cai F, Kerchner GA, Ayalon G, Bingol B, Sheng $M$, Hinds $D$, Behrens TW, Singleton $A B$, et al, International Parkinson's Disease Genomics Consortium, and 23andMe Research Team. A metaanalysis of genome-wide association studies identifies 17 new Parkinson's disease risk loci. Nat Genet. 2017; 49:1511-16.

https://doi.org/10.1038/ng.3955

PMID:28892059

54. Li G, Cui S, Du J, Liu J, Zhang P, Fu Y, He Y, Zhou H, Ma J, Chen S. Association of GALC, ZNF184, IL1R2 and ELOVL7 With Parkinson's Disease in Southern Chinese. Front Aging Neurosci. 2018; 10:402. https://doi.org/10.3389/fnagi.2018.00402 PMID:30618709

55. Saiki S, Hatano T, Fujimaki M, Ishikawa KI, Mori A, Oji Y, Okuzumi A, Fukuhara T, Koinuma T, Imamichi $Y$, Nagumo M, Furuya N, Nojiri S, et al. Decreased longchain acylcarnitines from insufficient $\beta$-oxidation as potential early diagnostic markers for Parkinson's disease. Sci Rep. 2017; 7:7328.

https://doi.org/10.1038/s41598-017-06767-y PMID:28779141

56. Sharon R, Goldberg MS, Bar-Josef I, Betensky RA, Shen J, Selkoe DJ. alpha-Synuclein occurs in lipid-rich high molecular weight complexes, binds fatty acids, and shows homology to the fatty acid-binding proteins. Proc Natl Acad Sci USA. 2001; 98:9110-15. https://doi.org/10.1073/pnas.171300598 PMID: 11481478

57. Karube H, Sakamoto M, Arawaka S, Hara S, Sato H, Ren $\mathrm{CH}$, Goto S, Koyama S, Wada M, Kawanami T, Kurita K, Kato T. N-terminal region of alpha-synuclein is essential for the fatty acid-induced oligomerization of the molecules. FEBS Lett. 2008; 582:3693-700. https://doi.org/10.1016/i.febslet.2008.10.001 PMID: 18848547 
58. Golovko MY, Faergeman NJ, Cole NB, Castagnet PI, Nussbaum RL, Murphy EJ. Alpha-synuclein gene deletion decreases brain palmitate uptake and alters the palmitate metabolism in the absence of alphasynuclein palmitate binding. Biochemistry. 2005; 44:8251-59.

https://doi.org/10.1021/bi0502137 PMID:15938614

59. Golovko MY, Rosenberger TA, Faergeman NJ, Feddersen S, Cole NB, Pribill I, Berger J, Nussbaum RL, Murphy EJ. Acyl-CoA synthetase activity links wild-type but not mutant alpha-synuclein to brain arachidonate metabolism. Biochemistry. 2006; 45:6956-66. https://doi.org/10.1021/bi0600289 PMID:16734431

60. Golovko MY, Rosenberger TA, Feddersen S, Faergeman NJ, Murphy EJ. Alpha-synuclein gene ablation increases docosahexaenoic acid incorporation and turnover in brain phospholipids. J Neurochem. 2007; 101:201-11. https://doi.org/10.1111/i.1471-4159.2006.04357.x PMID: 17250657

61. Ingram TL, Shephard F, Sarmad S, Ortori CA, Barrett DA, Chakrabarti L. Sex specific inflammatory profiles of cerebellar mitochondria are attenuated in Parkinson's disease. Aging (Albany NY). 2020; 12:17713-37. https://doi.org/10.18632/aging.103937 PMID: $\underline{32855358}$

62. Lipton SA, Kim WK, Choi YB, Kumar S, D'Emilia DM, Rayudu PV, Arnelle DR, Stamler JS. Neurotoxicity associated with dual actions of homocysteine at the $\mathrm{N}$ methyl-D-aspartate receptor. Proc Natl Acad Sci USA. 1997; 94:5923-28.

https://doi.org/10.1073/pnas.94.11.5923 PMID: $\underline{159176}$

63. Müller T, Werne B, Fowler B, Kuhn W. Nigral endothelial dysfunction, homocysteine, and Parkinson's disease. Lancet. 1999; 354:126-27. https://doi.org/10.1016/s0140-6736(99)01660-8 PMID:10408491

64. Duan W, Ladenheim B, Cutler RG, Kruman II, Cadet JL, Mattson MP. Dietary folate deficiency and elevated homocysteine levels endanger dopaminergic neurons in models of Parkinson's disease. J Neurochem. 2002; 80:101-10.

https://doi.org/10.1046/i.0022-3042.2001.00676.x PMID:11796748

65. Martignoni E, Tassorelli C, Nappi G, Zangaglia R, Pacchetti C, Blandini F. Homocysteine and Parkinson's disease: a dangerous liaison? J Neurol Sci. 2007; 257:31-37.

https://doi.org/10.1016/i.jns.2007.01.028 PMID:17336337

66. Mayer O, Filipovský J, Hromádka M, Svobodová V, Racek J, Mayer O Jr, Stehlík P, Trefil L, Zárybnická M.
Treatment of hyperhomocysteinemia with folic acid: effects on homocysteine levels, coagulation status, and oxidative stress markers. J Cardiovasc Pharmacol. 2002; 39:851-57.

https://doi.org/10.1097/00005344-200206000-00010 PMID:12021579

67. Maron BA, Loscalzo J. The treatment of hyperhomocysteinemia. Annu Rev Med. 2009; 60:39-54.

https://doi.org/10.1146/annurev.med.60.041807.1233 08 PMID:18729731

68. Shen L. Associations between B Vitamins and Parkinson's Disease. Nutrients. 2015; 7:7197-208. https://doi.org/10.3390/nu7095333 PMID:26343714

69. Xie Y, Feng H, Peng S, Xiao J, Zhang J. Association of plasma homocysteine, vitamin B12 and folate levels with cognitive function in Parkinson's disease: A metaanalysis. Neurosci Lett. 2017; 636:190-95. https://doi.org/10.1016/i.neulet.2016.11.007 PMID:27840145

70. Shen Y, Dong ZF, Pan PL, Xu G, Huang JY, Liu CF. Association of homocysteine, folate, and white matter hyperintensities in Parkinson's patients with different motor phenotypes. Neurol Sci. 2019; 40:1855-63. https://doi.org/10.1007/s10072-019-03906-3 PMID:31055730

71. Dong B, Wu R. Plasma homocysteine, folate and vitamin B12 levels in Parkinson's disease in China: A meta-analysis. Clin Neurol Neurosurg. 2020; 188:105587.

https://doi.org/10.1016/i.clineuro.2019.105587 PMID:31733593

72. Liu S, Lu B. Reduction of protein translation and activation of autophagy protect against PINK1 pathogenesis in Drosophila melanogaster. PLoS Genet. 2010; 6:e1001237.

https://doi.org/10.1371/journal.pgen.1001237 PMID:21151574

73. Morel E, Chamoun Z, Lasiecka ZM, Chan RB, Williamson RL, Vetanovetz C, Dall'Armi C, Simoes S, Point Du Jour KS, McCabe BD, Small SA, Di Paolo G. Phosphatidylinositol-3-phosphate regulates sorting and processing of amyloid precursor protein through the endosomal system. Nat Commun. 2013; 4:2250. https://doi.org/10.1038/ncomms3250 PMID:23907271

74. Khadilkar RJ, Rodrigues D, Mote RD, Sinha AR, Kulkarni V, Magadi SS, Inamdar MS. ARF1-GTP regulates Asrij to provide endocytic control of Drosophila blood cell homeostasis. Proc Natl Acad Sci USA. 2014; 111:4898-903.

https://doi.org/10.1073/pnas.1303559111 PMID:24707047 
75. Li X, Wang L, Cykowski M, He T, Liu T, Chakranarayan J, Rivera A, Zhao H, Powell S, Xia W, Wong ST. OCIAD1 contributes to neurodegeneration in Alzheimer's disease by inducing mitochondria dysfunction, neuronal vulnerability and synaptic damages. EBioMedicine. 2020; 51:102569.

https://doi.org/10.1016/i.ebiom.2019.11.030

PMID:31931285

76. Shetty DK, Kalamkar KP, Inamdar MS. OCIAD1 Controls Electron Transport Chain Complex I Activity to Regulate Energy Metabolism in Human Pluripotent Stem Cells. Stem Cell Reports. 2018; 11:128-41.

https://doi.org/10.1016/i.stemcr.2018.05.015

PMID:29937147

77. Cherwinski HM, Cohn RG, Cheung P, Webster DJ, Xu YZ, Caulfield JP, Young JM, Nakano G, Ransom JT. The immunosuppressant leflunomide inhibits lymphocyte proliferation by inhibiting pyrimidine biosynthesis. J Pharmacol Exp Ther. 1995; 275: 1043-49.

PMID:7473131

78. Miret-Casals L, Sebastián D, Brea J, Rico-Leo EM, Palacín M, Fernández-Salguero PM, Loza MI, Albericio F, Zorzano A. Identification of New Activators of Mitochondrial Fusion Reveals a Link between Mitochondrial Morphology and Pyrimidine Metabolism. Cell Chem Biol. 2018; 25:268-78.e4. https://doi.org/10.1016/j.chembiol.2017.12.001 PMID:29290623
79. Fang J, Uchiumi T, Yagi M, Matsumoto S, Amamoto R, Takazaki S, Yamaza H, Nonaka K, Kang D. Dihydroorotate dehydrogenase is physically associated with the respiratory complex and its loss leads to mitochondrial dysfunction. Biosci Rep. 2013; 33:e00021.

https://doi.org/10.1042/BSR20120097

PMID:23216091

80. Tufi R, Gandhi S, de Castro IP, Lehmann S, Angelova PR, Dinsdale D, Deas E, Plun-Favreau $H$, Nicotera $P$, Abramov AY, Willis AE, Mallucci GR, Loh SH, Martins LM. Enhancing nucleotide metabolism protects against mitochondrial dysfunction and neurodegeneration in a PINK1 model of Parkinson's disease. Nat Cell Biol. 2014; 16:157-66.

https://doi.org/10.1038/ncb2901 PMID:24441527

81. Cheedipudi SM, Hu J, Fan S, Yuan P, Karmouch J, Czernuszewicz G, Robertson MJ, Coarfa C, Hong K, Yao $Y$, Campbell H, Wehrens X, Gurha P, Marian AJ. Exercise restores dysregulated gene expression in a mouse model of arrhythmogenic cardiomyopathy. Cardiovasc Res. 2020; 116:1199-213. https://doi.org/10.1093/cvr/cvz199 PMID:31350552

82. Piazza N, Gosangi B, Devilla S, Arking R, Wessells R. Exercise-training in young Drosophila melanogaster reduces age-related decline in mobility and cardiac performance. PLoS One. 2009; 4:e5886. https://doi.org/10.1371/journal.pone.0005886 PMID:19517023 


\section{SUPPLEMENTARY MATERIALS}

\section{Ingram counter-balanced exerciser}

Our bespoke Ingram Counter-balanced Exercise (ICE) machine was adapted from the PT design of Piazza et al., by Mr. John Ingram (TI's father) [82]. The exerciser fits into an incubator with internal dimensions of $48 \mathrm{x}$ $48 \times 35 \mathrm{~cm}$ and provides a vertically moving tray measuring $30 \quad$ x $34 \mathrm{~cm}$. A solenoid-powered counterbalanced lever causes the tray to be lifted $3 \mathrm{~cm}$. The tray is lifted and immediately dropped every 15 seconds.

Counterbalancing the lever are a series of springs, which can be adjusted to allow lifts of up to $3.0 \mathrm{~kg}$. Springs efficiently store and release energy enabling a more rapid drop than would be the case if weights were used. They also reduce the size and overall weight of the device.

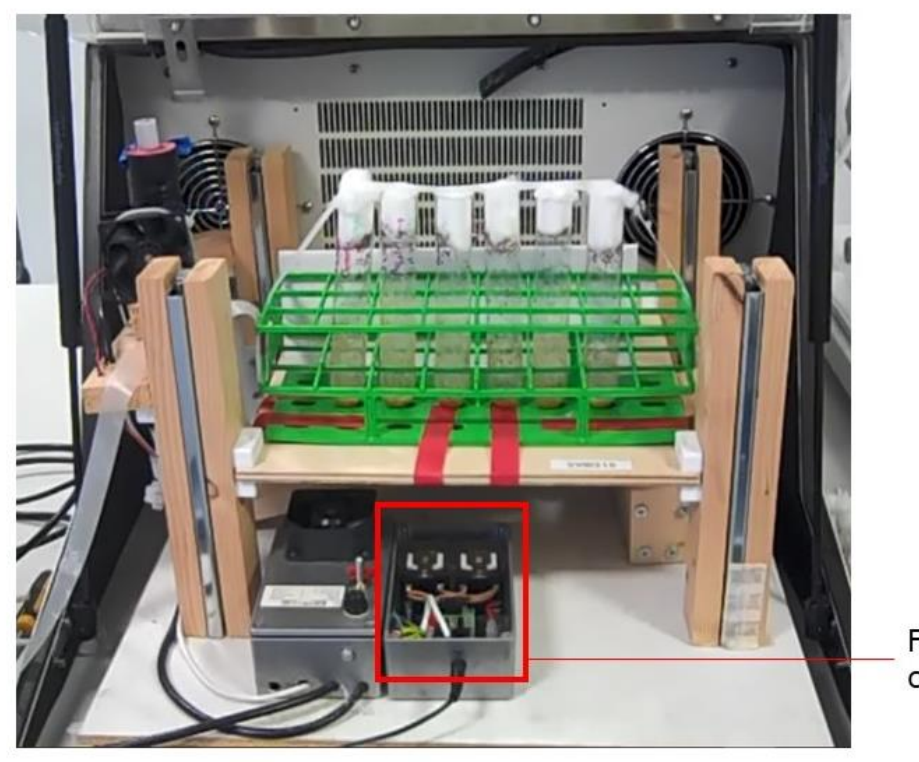

Lift is provided by a solenoid wound onto a nylon core and fixed to the body of the exerciser. The steel armature passing through the solenoid is attached to the counterbalanced lever. Activation of the solenoid causes the armature to rise which lifts the lever.

Solenoid activation is controlled by an astable timer. This triggers a relay to pulse the applied AC voltage. Two capacitors acting as a loss-less resistor allow the voltage to be reduced without producing excess heat, before it is rectified, smoothed and finally applied to the solenoid. Powering with DC current causes less vibration and heat generation in the solenoid but, as the capacitors and the solenoids both work more efficiently at lower temperatures, any excess heat is subsequently dissipated by proximate fans. Using a pulse of current as described rather than the discharge from a large capacitor to activate the solenoid saves space, it is also safer as there is far less stored energy.
Frequency

control point 


\section{Supplementary Figure}

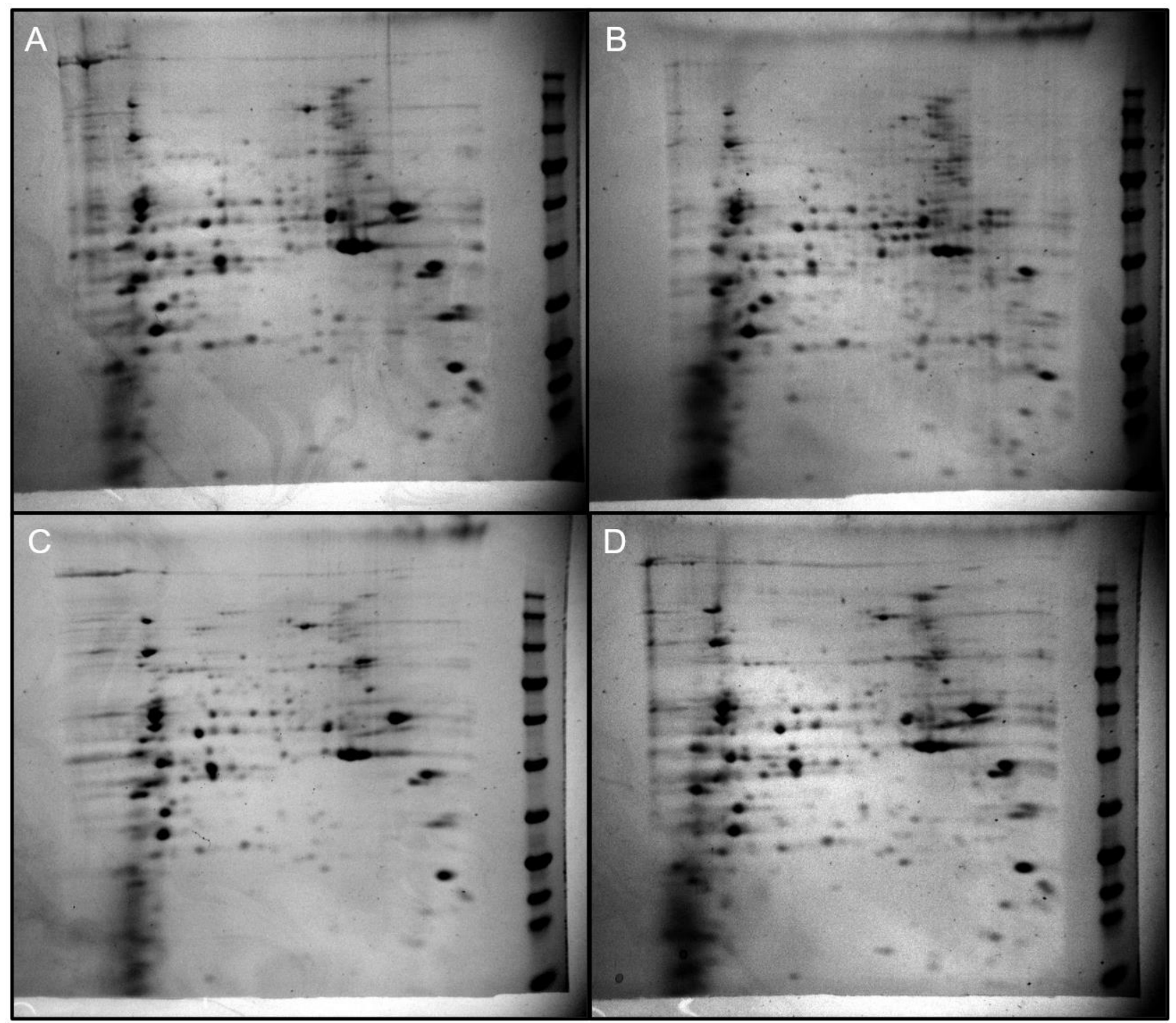

Supplementary Figure 1. Representative 2DE gels of (A) exercised Pink1, (B) non-exercised Pink1, (C) exercised wildtype, (D) non-exercised wildtype Drosophila melanogaster. 


\section{Supplementary Tables}

Please browse Full Text version to see the data of Supplementary Tables 1-5.

Supplementary Table 1. Label-free MS identified 516 proteins from the mitochondrial fractions of Pink1 ${ }^{-}$and WT D. melanogaster.

Supplementary Table 2. Label-free MS identified 105 proteins with different abundance when comparing nonexercised Pink1 ${ }^{-}$and wildtype flies.

Supplementary Table 3. Label-free MS identified 57 proteins with altered abundance between exercised and non-exercised Pink1 flies, 55 of which had decreased abundance.

Supplementary Table 4. Label-free MS identified 56 proteins with different abundance when comparing exercised Pink1 ${ }^{-}$and exercised WT flies.

Supplementary Table 5. Label-free MS identified 55 proteins with different abundance when comparing exercised Pink1 and non-exercised WT flies. 